\title{
Summary of Applications of TOUGH2 \\ to the Evaluation of Multiphase Flow Processes at the WIPP
}

\author{
Stephen W. Webb, Kurt W. Larson, Geoff A. Freeze ${ }^{1}$, and Tracy L. Christian-Frear ${ }^{2}$ \\ Sandia National Laboratories \\ Albuquerque, NM 87185
}

\section{Introduction}

The Waste Isolation Pilot Plant (WIPP) is a U.S. Department of Energy (DOE) research and development facility for the underground disposal of transuranic waste in southeastern New Mexico. The WIPP repository is located $655 \mathrm{~m}$ below the land surface in the lower portion of the Salado Formation, which is comprised of beds of pure and impure halite with thin interbeds of anhydrite and related clay seams. The regional dip of the Salado Formation is approximately $1^{\circ}$ southeast in the vicinity of the repository. The proposed waste storage area has eight waste disposal panels, each of which will contain seven rooms (Figure 1). The repository is designed to follow a single stratigraphic horizon. Due to the dip, the north end of the repository will be about 10 meters higher than the south end.

Waste that is emplaced in the disposal rooms will generate gas due to microbial degradation, anoxic corrosion, and radiolysis. Brine inflow to the rooms from the surrounding Salado Formation may significantly influence the gas generation rate and the total amount of gas generated. The salt surrounding the repository will creep in response to the excavation, reducing the room volume. Gas generation in the room may increase the pressure sufficiently to drive brine and gas into the surrounding Salado Formation. Migration of gas and brine in the Salado is an important factor in evaluating the performance of the repository.

The studies summarized in this paper have. been performed to evaluate brine and gas flow processes in the WIPP disposal system and to identify some of the important processes. These studies are done in support of, but are not part of, the formal Performance Assessment (PA) effort. Because of probabilistic and system-scale requirements, the PA effort uses the Sandiadeveloped BRAGFLO (BRine. And Gas FLOw) code for multiphase flow calculations.

\section{Repository Modeling Studies}

Our studies to date have generally been limited to two-dimensional modeling of a single room, although some three-dimensional modeling has been performed and more is planned. Early studies of brine inflow and gas migration used the ECLIPSE code. While this code was adequate for early analyses, TOUGH2 was selected for current use due to the availability of the source code and its use on the Yucca Mountain Project.

Most early studies of the response of the repository assumed a constant volume room (Webb, 1992a) for simplicity. However, time-dependent creep closure and pressure-induced re-inflation

IINTERA, Inc., Albuquerque, NM

${ }^{2}$ RE/SPEC, Inc., Albuquerque, NM

This work was supported by the United

States Depariment of Energy under

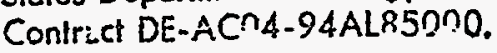




\section{DISCLAIMER}

This report was prepared as an account of work sponsored by an agency of the United States Government. Neither the United States Government nor any agency thereof, nor any of their employees, make any warranty, express or implied, or assumes any legal liability or responsibility for the accuracy, completeness, or usefulness of any information, apparatus, product, or process disclosed, or represents that its use would not infringe privately owned rights. Reference herein to any specific commercial product, process, or service by trade name, trademark, manufacturer, or otherwise does not necessarily constitute or imply its endorsement, recommendation, or favoring by the United States Government or any agency thereof. The views and opinions of authors expressed herein do not necessarily state or reflect those of the United States Government or any agency thereof. 


\section{DISCLAIMER}

Portions of this document may be illegible in electronic image products. Images are produced from the best available original document. 
of the repository could have a significant impact on repository performance. Attempts to model salt creep and repository closure through the flow of a highly-viscous fluid (salt) were performed using ECLIPSE (Davies et al., 1992). As the transition was made to TOUGH2, similar modifications were made resulting in a special air-water-oil equation of state, EOS8, in which the flow of the oil phase simulates salt creep as given by Freeze, et al. (these proceedings).

While this approach was an improvement over a constant room volume calculation, questions about the applicability of the approach in general have led to the development of PHENIX, which crudely couples TOUGH2 and a rock mechanics code, SANTOS (Stone, in preparation). The PHENIX code simply passes appropriate parameters between TOUGH2 and SANTOS every few time steps. While this coupling is crude, it is an improvement over the EOS8 module.

A number of other studies have been performed to evaluate assumptions made in the development of the Performance Assessment (PA) model. Due to computational constraints related to the large number of Monte Carlo simulations and the need to model the repository geosphere system, PA uses a highly simplified repository and Salado Formation model. For example, due to the relatively small dip of the formation $\left(\sim 1^{\circ}\right)$, a horizontal configuration has been assumed. In addition, the number of stratigraphic layers represented in the Salado Formation is limited. The PA model is also a hybrid 2D/3D model assuming radial symmetry. The room/panel/repository model is extremely simplified even though waste properties such as permeability vary orders of magnitude. These and other assumptions have been or are planned to be evaluated using more detailed TOUGH2 modeling.

The regional dip of the Salado, even though only about $1^{\circ}$, has the potential to significantly alter some of the two-phase flow behavior. If a horizontal configuration is assumed, only cocurrent two-phase flow is likely. If the configuration is not horizontal, countercurrent two-phase flow is possible. In the case of the WIPP repository, the inclusion of this $1^{\circ}$ dip may increase brine inflow by about 50 percent due to counterflow in the anhydrite interbeds. In addition, due to buoyancy forces, gas migration distances may be dramatically increased when dip is included as shown by Webb and Larson (these proceedings).

There are about 40 distinctive stratigraphic layers within 10 meters vertically of the repository, consisting of units of anhydrite, argillaceous halite, polyhalitic halite, and pure halite. The present PA model lumps two of the anhydrite layers together, and represents all the nonanhydrite layers by a single composite impure halite material. The difference in the layering detail is shown in Figure 2, where LAY and PAL refer to the detailed and PA schemes, respectively. A room model using both layering schemes has been examined by Christian-Frear and Webb (in review) to evaluate the performance differences between the two representations.

Figure 3 compares a variety of cases with the two layering schemes. For any one variation, such as the base case or interbed fracture, the results are similar. Differences in repository pressurization and brine inflow due to the two layering schemes are quite small, while gas migration distances show a moderate influence of the layering detail. Based on these results, explicit representation of the individual layers is probably not warranted in the PA model, 
especially when repository pressure and brine inflow are the main performance measures. If gas migration distance is the main issue, additional stratigraphic layering detail may be necessary.

Additional studies planned include development of a full three-dimensional model of the repository. The TOUGH2 integrated finite difference method offers significant advantages over standard finite difference meshes in that detail in certain regions can be included without.altering the entire model domain. For example, one of the panels may be broken up into separate rooms, while the other panels use a lumped representation. Unlike the traditional finite difference approach, this added detail will not affect other parts of the mesh.

Fracturing of the anhydrite interbeds may occur if the repository pressure approaches lithostatic. Development of a dual permeability and/or dual porosity model of fractured interbeds is another planned activity. The dual continuum capability of TOUGH2 will be used to evaluate the simplified porous medium representation currently used by PA.

Finally, development of a detailed model of a room is planned. Each room will contain waste with widely varying porosity and permeability. If the repository pressurizes, gas and brine will tend to move out of the repository and into the interbeds. Due to the variation of physical properties and the stratigraphic dip, significant nonuniform behavior is possible, and large regions of brine may be left behind that may continue to generate gas. A detailed room model is planned to address heterogeneity issues in the room.

\section{Salado Data Interpretation Studies}

In addition to the modeling studies described above, TOUGH 2 has been used as a data interpretation and sensitivity analysis tool. Brine inflow is an important parameter for the WIPP. As part of the evaluation of brine inflow data into open boreholes, Webb (1992b) and Christian-Frear (1993) performed one- and two-dimensional sensitivity studies considering such factors as dissolved gas exsolution, free gas, multipie boreholes, the effect of a room on brine inflow to a borehole, and stratigraphic layering. Brine inflow data are also being collected in Room Q, a large 9.5-ft diameter 300-ft long circular room which has been sealed off in order to collect brine inflow data. Interpretation of the brine inflow and surrounding pore pressure data with TOUGH2 and ITOUGH is planned.

As part of the Salado testing program, packed-off sections of boreholes are tested to evaluate formation parameters in different units at various distances from the repository. Some threshold pressure tests were conducted in a packed-off borehole to try to estimate the threshold pressure of an anhydrite layer. These data were interpreted using TOUGH2 to evaluate different sets of two-phase characteristic curves.

\section{Non-Salado Studies}

In some WIPP human intrusion scenarios, brine from pressurized brine reservoirs in the Castile Formation below the Salado is assumed to flow into the repository through a borehole, and 
repository fluids (gas and brine) are released into the overlying Culebra Formation. Currently, flow in the Culebra has only been analyzed as a variable density brine, neglecting the effect of the gas. To address this concern, an air-water-brine equation of state, EOS7, was developed in which the brine and water were miscible. EOS7 was tested by comparison to the variable density brine analysis done with SWIFT II as summarized by Christian-Frear and Webb (1995). Extension to brine and gas flow in the Culebra is possible in the near future.

\section{Conclusions}

TOUGH2 has been shown to be a powerful and versatile multiphase analysis tool for the WIPP, useful for repository modeling, data interpretation, and PA model evaluation. It has shown where PA model simplifications have significant impact on the results, such as in ignoring dip, and has indicated where existing PA models are sufficient, such as in the stratigraphic layering detail. Additional studies evaluating other features of the PA model are planned.

\section{References}

Christian-Frear, T.L. (1993), Simulations of Brine Inflow into a Waste Isolation Pilot Plant Borehole: Results of Two-Dimensional Numerical Sensitivity Studies, Topical Report RSI/ALO 1993-470, RE/SPEC, Inc., Albuquerque, NM.

Christian-Frear, T.L., and S.W. Webb (in review), The Effect of Explicit Representation of the Stratigraphy on Brine and Gas Flow at the Waste Isolation Pilot Plant, SAND94-3173, Sandia National Laboratories.

Christian-Frear, T.L., and S.W. Webb (these proceedings), "Modification and Application of TOUGH2 as a Saturated Flow Code and Comparison to SWIFT Results.".

Davies, P.B., L.H. Brush, and F.T. Mendenhall (1992), "Assessing the Impact of WasteGenerated Gas From the Degradation of Transuranic Waste at the Waste Isolation Pilot Plant (WIPP): An Overview of Strongly Coupled Chemical, Hydrological, and Structural Processes, " Gas Generation and Release from Radioactive Waste Repositories, Aix-enProvence, France, Nuclear Energy Agency, OECD, pp. 55-74.

Freeze, G.A., K.W. Larson, P.B. Davies, and S.W. W.ebb (these proceedings), "Using a Multiphase Flow Code to Model the Coupled Effects of Repository Consolidation and Multiphase Brine and Gas Flow at the Waste Isolation Pilot Plant."

Stone, C.M. (in preparation), "SANTOS - A Two-Dimensional Finite Element Program for the Quasistatic, Large Deformation, Inelastic Response of Solids," SAND90-0543, Sandia National Laboratories.

Webb, S.W. (1992a), "Sensitivity Studies for Gas Release From the Waste Isolation Pilot Plant (WIPP)," Gas Generation and Release from Radioactive Waste Repositories, Aix-enProvence, France, Nuclear Energy Agency, OECD, pp.310-326.

Webb, S.W. (1992b), Brine Inflow Sensitivity Study for Waste Isolation Pilot Plant Boreholes: Results of One-Dimensional Simulations, SAND91-2296, Sandia National Laboratories.

Webb, S.W., and K.W. Larson (these proceedings), "The Effect of Stratigraphic Dip on Multiphase Flow at the Waste Isolation Pilot Plant." 

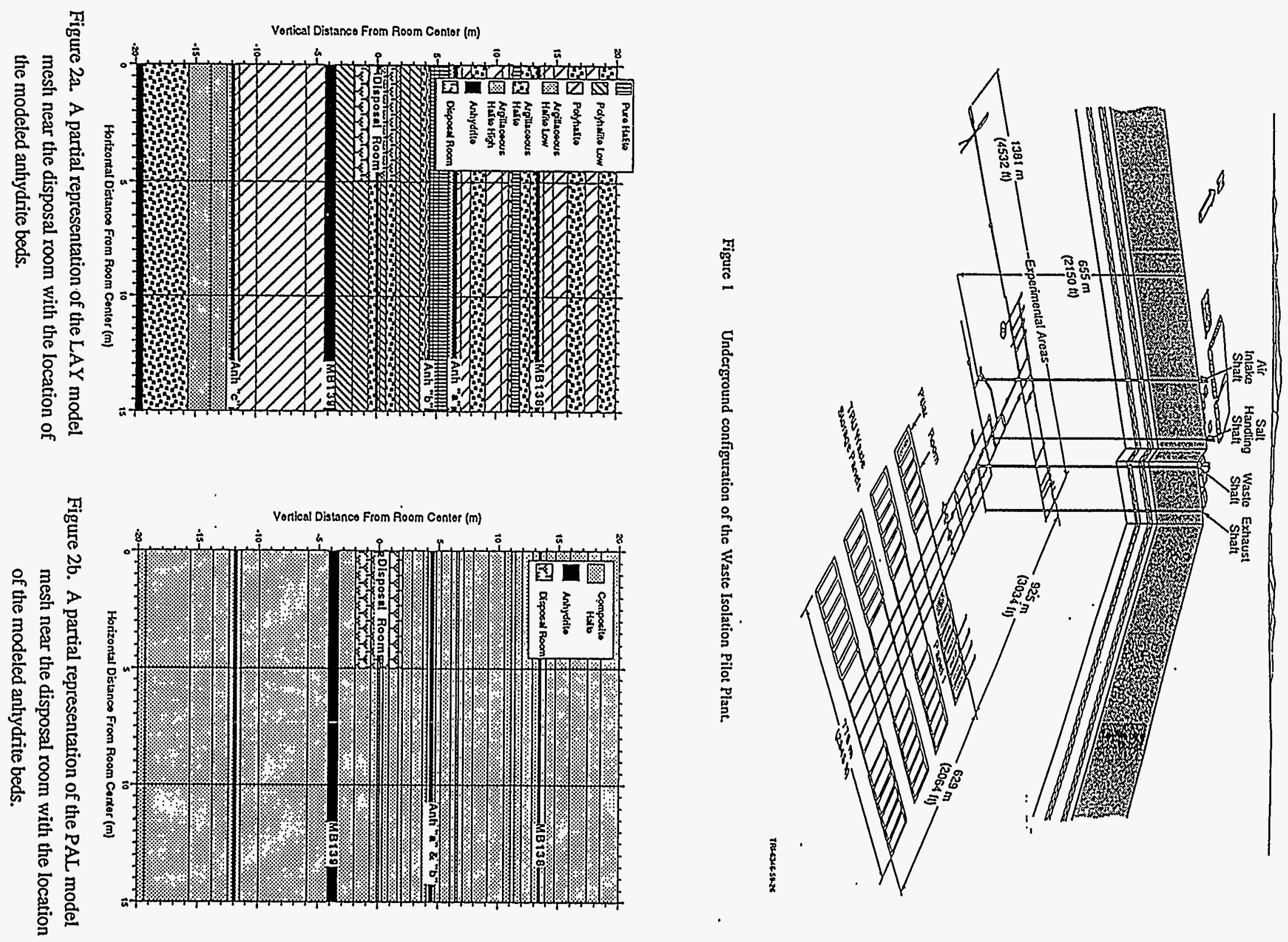


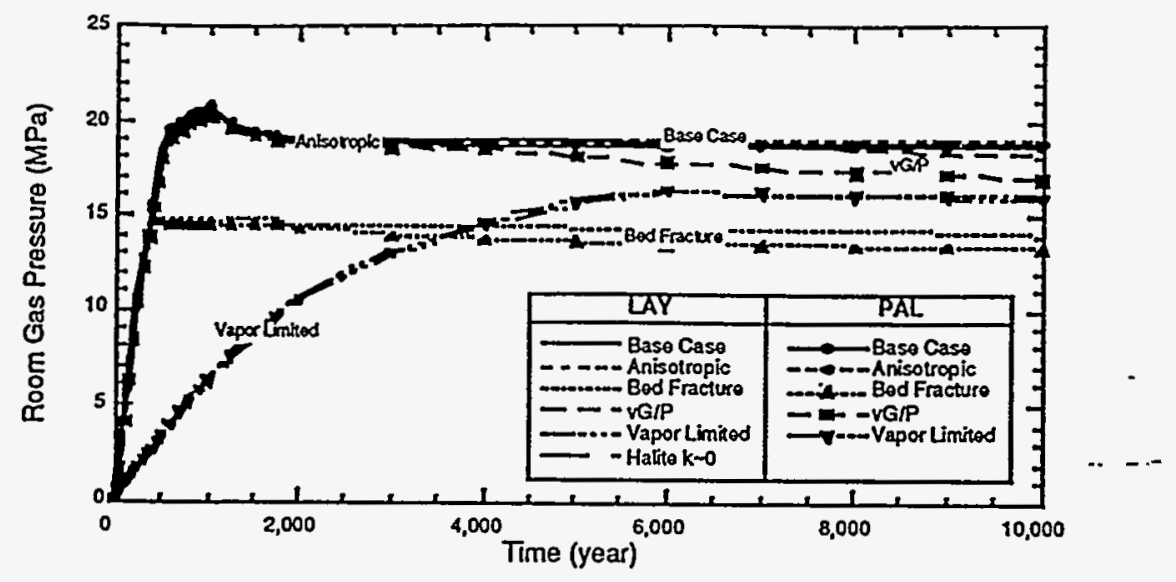

3a. Repository pressure.

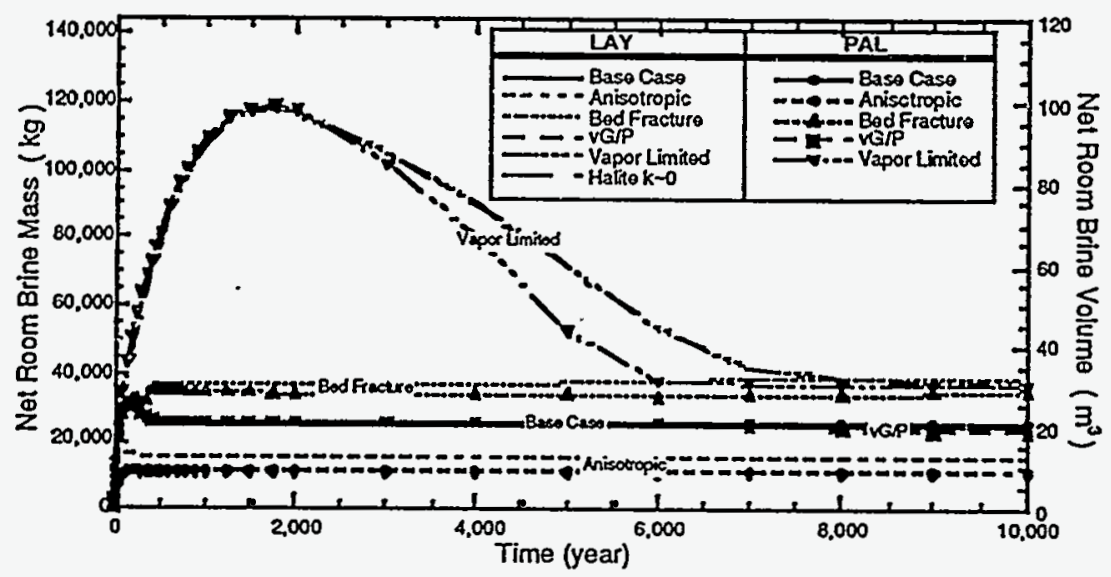

3b. Brine inflow into the repository

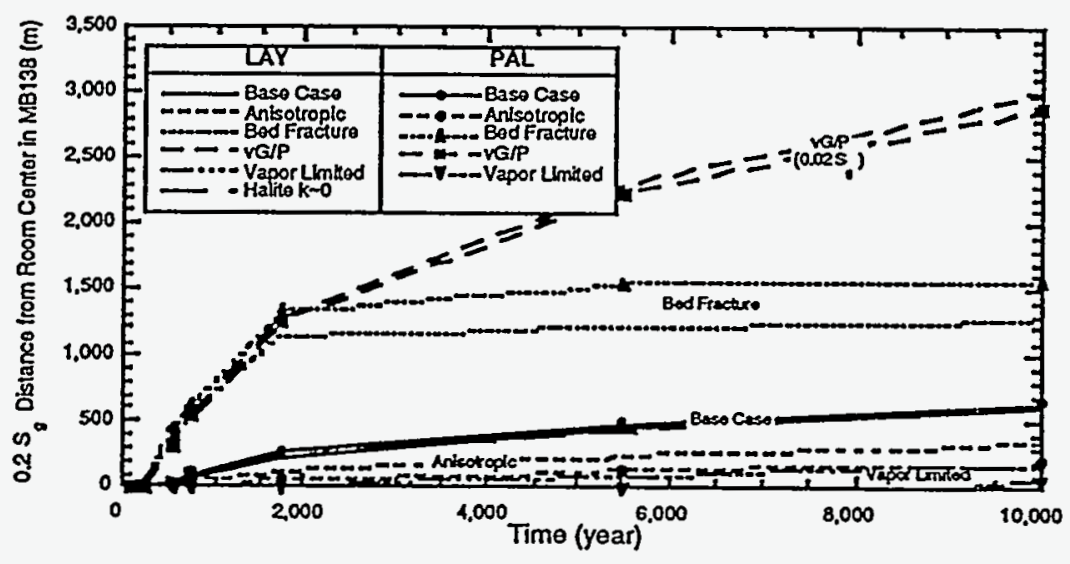

3c. Gas migration distance.

Figure 3. Effect of stratigraphic layering detail. 